\title{
Pressure distribution around the thermal envelope - a parametric study of the impact from wind and temperature on contaminant transport within a building
}

\author{
Fredrik Domhagen*, Paula Wahlgren, Carl-Eric Hagentoft \\ Chalmers University of Technology, Sven Hultins gata 6, 41258 Gothenburg, Sweden
}

\begin{abstract}
Several school buildings in Sweden have indoor air quality problems. The contaminant source is often assumed to come from within the construction, for example from the crawl space or attic space. Contaminants, in these cases, are transported by air leaking between compartments in the building. Here, the driving force for the air leakage is difference in pressure and, therefore, determining pressure also determines the direction of contaminant transport. In many cases, measures to improve the air quality are taken without a thorough understanding of how it might affect the pressure distribution in the building. In this paper a numerical model is used to examine how different climate scenarios and different building configurations affect the leakage and contaminant transport in a building with a crawl space. Results show that for leaky buildings the ventilation rate increases with increased wind and therefore the contaminant concentration decreases. The worst scenario in terms of high contaminant concentration is mild days with little wind. Also, when installing an exhaust fan in the crawl space with the purpose to prevent air from leaking from the crawl space to the classroom it is advisable to also consider the airtightness and the climate, not only the pressure difference across the floor.
\end{abstract}

\section{Background}

Some school buildings in Sweden have indoor air quality problems and contaminants are often assumed to come from the crawl space or the attic space. The type of contaminants is in most cases unknown but is sensed by the teachers and pupils in the school and causes discomfort. Transport of mould spores from the crawl space to the indoor air was investigated in [1] resulting in the conclusion that a building with a crawl space and a pressure difference over the floor could be a potential risk for indoor air quality problems.

The contaminants are transported between the compartments in leakages in the construction. These leakages are usually situated at penetrations or at joints. Here, the driving force for the air leakage is differences in pressure between the compartments. The pressure differences also determine the direction of the air leakage. In order to take efficient measures to prevent contaminants from reaching the classroom, it is important to understand how the pressure distribution is affected by different climate scenarios and different building configurations. The purpose of this paper is to investigate in what way different climate scenarios and building configurations affect the pressure difference between crawl space and classroom as well as concentration levels in the classroom.

This paper is a part of a project that deals with measures to decrease indoor air problems in schools, which includes both numerical simulation and measurements. Measurements on contaminant transport can be found in for example, [2] and [3], which investigate building pressures including dependence on wind speed and wind direction, and describes measurements on pressure differences across the floor above a crawl space in a school building. In this paper, numerical simulations on pressure differences over the floor above a crawl space and on contaminant levels for several cases are presented.

\section{Method}

An air flow model that describe contaminant transport in a building require calculation of building pressures and leakages between different zones. There are several numerical software products available for doing multizone air infiltration calculations [4]. However, these software products sometimes lack desirable features (for example presentation pressure profiles or tools for doing parametric studies) and, since they come as standalone executives, they are not easily extended with other tools. A multizone air infiltration model built in MATLAB is therefore used in this project. Using MATLAB allows for easy access to several useful tools and functions.

* Corresponding author: fredrik.domhagen@,chalmers.se 


\subsection{Numerical Tool}

The model uses a multizone airflow network technique like software products such as CONTAM [5] and COMIS [6]. Airflows between zones (classroom and crawl space) are defined using the power law equation, Equation 1.

$$
Q=C(P)^{n}
$$

where $\mathrm{Q}[\mathrm{kg} / \mathrm{s}]$ is the mass flow of air through the leakage, $\mathrm{P}[\mathrm{Pa}]$ is the pressure difference across the leakage, and $\mathrm{C}\left[\mathrm{m}^{3} /\left(\mathrm{sPa}^{\mathrm{n}}\right)\right]$ and $\mathrm{n}[-]$ are coefficients that depend on the type of leakage. Coefficient $n$ varies from 0.5 (turbulent orifice flow) to 1.0 (laminar flow). The coefficients $\mathrm{C}$ and $\mathrm{n}$ are typically obtained from measurements. However, if $\mathrm{n}$ is unknown a value of 0.65 (or 2/3) can be used as an estimate [7].

The model accounts for pressures caused by wind, stack effect and mechanical ventilation. These pressures are added together to get the total pressure difference [5]. The model assumes well mixed zones as well as no vertical temperature gradients in each zone. Airflows and zone pressures are found by solving the non-linear system of equations for a stationary scenario (when there is a mass balance in each zone).

Contaminants are transported only with moving air and there are no sink-effects included in the model. The contaminant source is simple and generate contaminants in the crawl space at a constant rate.

\subsection{Building Description}

The modelled building is a one storey building (one zone) with a crawl space (one zone) and a flat roof as illustrated in Figure 1. It is situated in a suburban area. Wind pressure coefficients are obtained from tables in [8] by assuming shielding conditions: "surrounded by obstructions equal to the height of the building". Most of the investigated school buildings are leaky (by Swedish standards) and therefore a total building airtightness of about $\mathrm{q}_{50}=1.0 \mathrm{1} / \mathrm{sm}^{2}$ at $50 \mathrm{~Pa}$ pressure difference is assumed. The building has a balanced ventilation system where the supply ventilation airflow is set to $90 \%$ of the exhaust ventilation air flow in the classroom. This way of adjusting the ventilation rates is common practice in Swedish buildings. The purpose is to create a pressure condition that prevents air from leaking through the thermal envelope from the inside to the outside and risking moisture condensation problems during colder periods.

Since the model does not aim at representing any particular building, the coefficient $\mathrm{n}$ in the power-law equation, Equation 1, is set to 0.65 for all leakages. Leakages usually occur at connections, for example floor/wall connection, but also in the crawl space floor. In one investigated school building [2], several leakages were detected in the inner door openings, which resulted in air flows between the crawl space to the classroom.

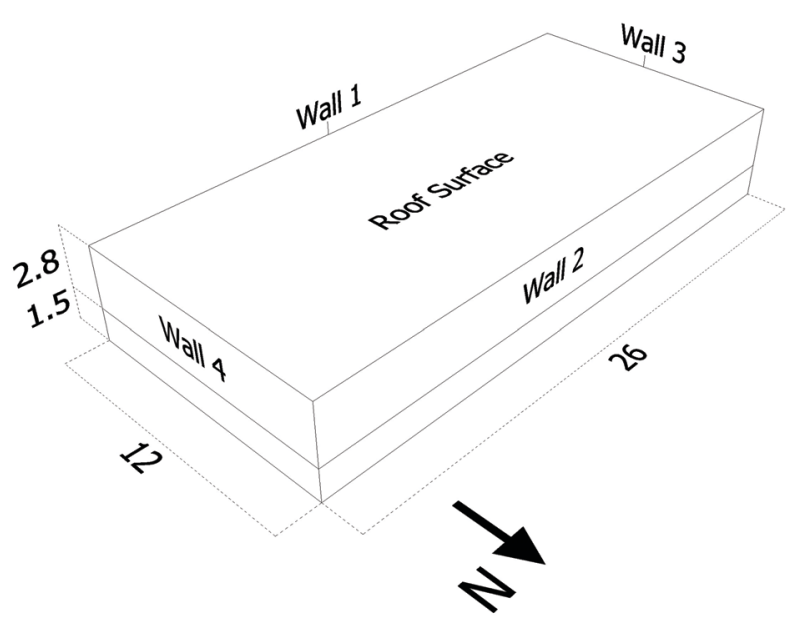

Fig. 1. Principle drawing of the modelled building showing north direction, surface labels and lengths in meters.

Air leakages can also be found in the roof construction, especially if there are many ventilation ducts and installations going through the roof construction. For a list of common leakages see [9].

\subsection{Presentation of Results}

The pressure difference between two compartments is dependent on the pressures in all adjacent spaces. The pressure of one compartment is caused by wind, stack effect and mechanical ventilation and the airtightness of the compartment. To understand the effect that different building configurations and climate scenarios has on the pressure difference is a complex task. A presentation convention is therefore introduced to facilitate the analysis and description of simulation results. An explanation of the presentation convention can be seen in Figure 2.

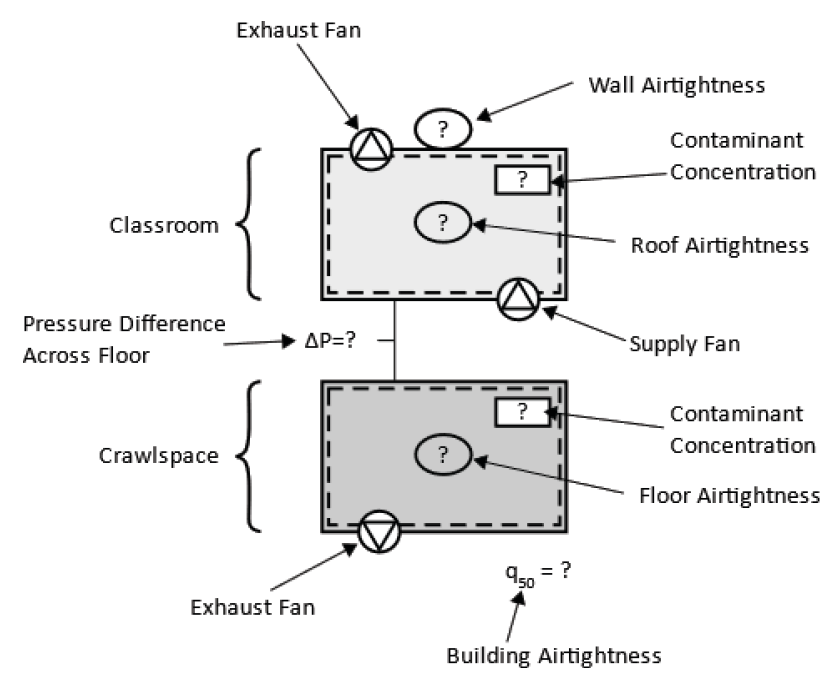

Fig. 2. Description of the presentation convention used for presenting results.

In Figure 2, the top rectangle represents the classroom and the bottom rectangle represents the crawl space. Each side of the rectangle has an airtightness 
value expressed as $\mathrm{q}_{50}\left(1 / \mathrm{sm}^{2}\right.$ at $50 \mathrm{~Pa}$ pressure difference).

The airtightness values in the middle of the rectangle shows the airtightness for either the roof or the floor. The pressure difference across the floor as well as airflow through the mechanical ventilation are also marked in the figure along with normalized contaminant concentrations. Contaminants in the air come from a source in the crawlspace that generates contaminants at a constant rate. The source strength is the same for all simulations. All concentrations are divided by the concentration in the crawlspace for the reference case, so that the concentrations are dimensionless and the concentration in the crawlspace for the reference case has a value of 1 . This facilitates comparison between different cases.

\subsection{Studied Scenarios}

Simulations are performed for different climate scenarios and for different building configurations (in total 15 building configurations). The climate scenarios relevant for this paper are summarized in Table 1. However, for the case study a total of 8 different climate scenarios were studied. Each simulation result is summarized according to Figure 2. For climate scenarios without wind, the pressure distribution across the thermal envelope is also presented in each figure.

Table 1. Climate scenarios used in the simulations. North wind direction means that the wind strikes the façade from the north, see Figure 1.

\begin{tabular}{|c|c|c|c|}
\hline $\begin{array}{c}\text { Climate } \\
\text { Scenario }\end{array}$ & $\begin{array}{c}\text { Outdoor } \\
\text { Temperature }\end{array}$ & $\begin{array}{c}\text { Wind } \\
\text { Speed }\end{array}$ & $\begin{array}{c}\text { Wind } \\
\text { Direction }\end{array}$ \\
\hline 1 & $-20^{\circ} \mathrm{C}$ & $0 \mathrm{~m} / \mathrm{s}$ & - \\
\hline 2 & $10^{\circ} \mathrm{C}$ & $5 \mathrm{~m} / \mathrm{s}$ & North \\
\hline $3 . \mathrm{a}$ & $15^{\circ} \mathrm{C}$ & $0 \mathrm{~m} / \mathrm{s}$ & - \\
\hline $3 . \mathrm{b}$ & $15^{\circ} \mathrm{C}$ & $15 \mathrm{~m} / \mathrm{s}$ & North \\
\hline 4 & $10^{\circ} \mathrm{C}$ & $5 \mathrm{~m} / \mathrm{s}$ & Northwest \\
\hline
\end{tabular}

The following building configurations: reference case, crawl space fan, tighter floor, tighter roof and tighter crawlspace are presented in this paper, along with two operation cases: exhaust fan in the crawl space and decreased ventilation in classroom.

In the reference case, the walls, roof and floor have an air permeability, q50, of $1.21 / \mathrm{sm}^{2}$ at $50 \mathrm{~Pa}$ and the walls in the crawlspace has a q50 corresponding to 2.0 $1 / \mathrm{sm}^{2}$. The ventilation system in the classroom is balanced and the ventilation rate is adjusted according to the Swedish building practice. For each building configuration, tighter roof, tighter floor and tighter crawlspace the air permeability, in terms of q50, is halved. The purpose of the exhaust fan in the case exhaust crawl space fan is to depressurize the crawl space and prevent air from leaking up to the classroom.

\section{Results}

Positive pressure difference across the crawl space floor means that air is leaking up to the classroom from the crawl space. The original air flow balance $(90 \%)$ through the ventilation system in the classroom is kept for each case, but the infiltration rate varies.

\subsection{Investigations of Variations in Airtightness}

Figure 2 shows simulation results for the reference case with climate scenario 1 in Table 1 . In this scenario the building operates as initially intended. There are no measures taken to prevent air from leaking from the crawl space to the classroom.
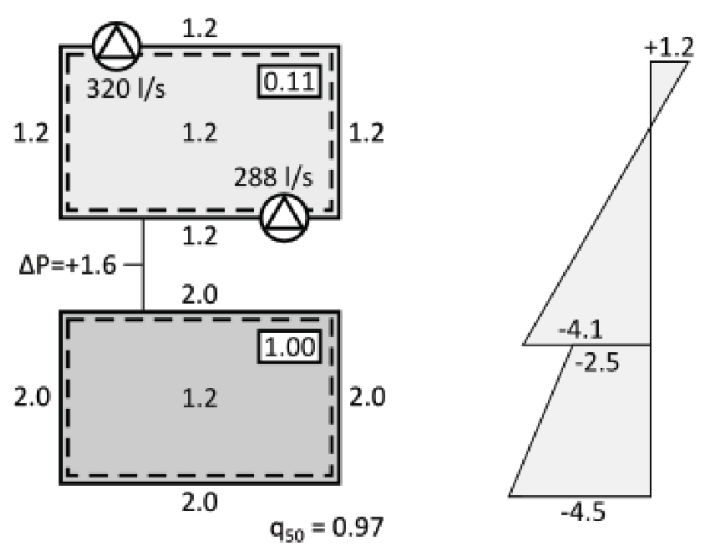

Fig. 3. Results from simulation of the reference case with climate scenario 1 . Positive pressure difference means that air is leaking from the crawl space to the classroom.

The neutral pressure plane is situated within the height of the classroom and the pressure difference across the floor is positive, which means that contaminants are coming up from the crawl space. The pressure difference across the floor is caused partly by the imbalanced ventilation system and partly by the stack effect.

Figure 4 shows simulation results with climate scenario 1 when the walls of the crawl space are made more airtight. Figure 4 shows that when the crawlspace walls are made more airtight, the neutral pressure plane in the crawl space is pushed upwards and the pressure difference across the floor is reduced (compared to the reference case, Figure 3). The contaminant concentration in the crawlspace increases compared to the reference case, since the ventilation rate is smaller. However, the air leakage from the crawlspace to the classroom decreases, because of reduced pressure difference. These counteracting effects are of the same magnitude and therefore the contaminant concentration in the classroom remains roughly the same as in the reference case, Figure 3. 

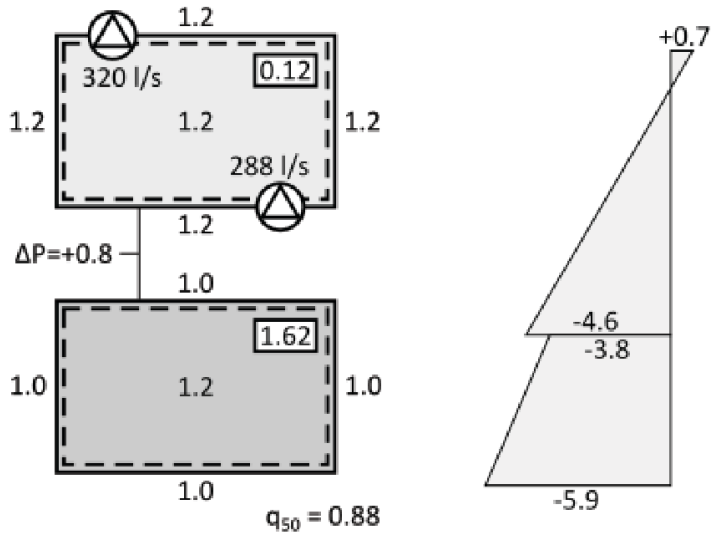

Fig. 4. Results from simulation with climate scenario 1 with tighter walls in the crawlspace. Positive pressure difference means that air is leaking from the crawl space to the classroom.

In Figure 5, simulation results can be seen for climate scenario 1 for a building configuration where the roof has been made more airtight. When compared to the reference case, Figure 3, the neutral pressure plane in the classroom is pushed further down. This reduces the pressure difference across the floor. However, also the ventilation rate of the classroom is reduced when the building is made more airtight. These two counteracting effects are of similar magnitude and therefore it is only a minor increase in contaminant concentration in the classroom when compared to the reference case.
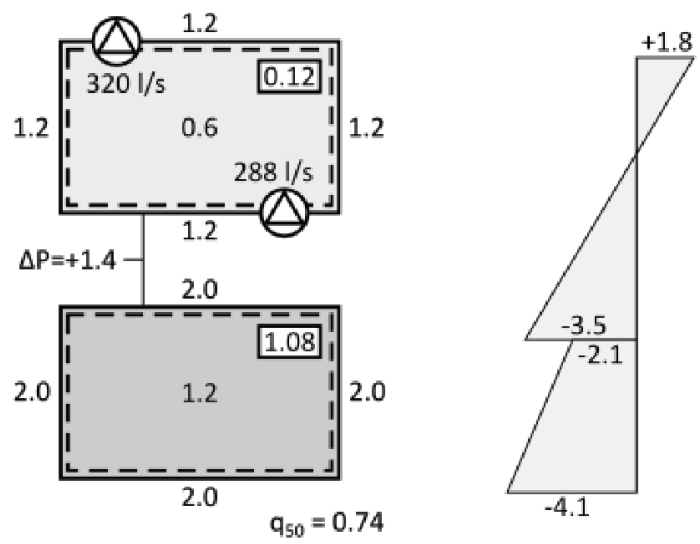

Fig. 5. Results from simulation with climate scenario 1 with a tighter roof. Positive pressure difference means that air is leaking from the crawl space to the classroom.

Figure 6 shows simulation results with climate scenario 1 for a building configuration where the floor is made more airtight. In this case the neutral pressure planes, when compared the reference case, Figure 3, in the classroom and the crawl space are pushed away from the floor and the pressure difference across the floor is therefore increased compared to the reference case. However, less air is leaking from the crawl space to the classroom, due to the smaller amount of leakages. Since the crawl space is more airtight the contaminant concentration is also higher. This is the reason why even though the leakage is smaller there is a small increase in contaminant concentration in the classroom compared to Figure 3. Considering the case when the floor is made more airtight in average, but when there is a larger remaining leakage, it will cause an increased air flow (with contaminants) in this particular location. In one of the investigated schools, major leakages were found around penetrations for electricity from the crawl space
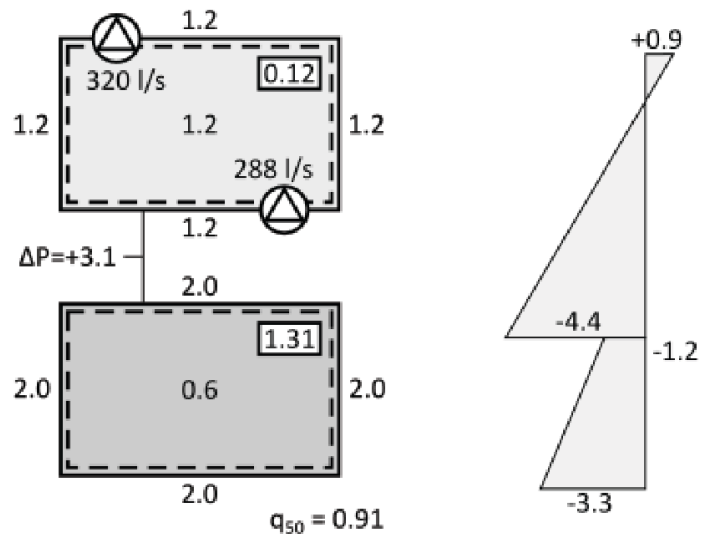

Fig. 6. Results from simulation with climate scenario 1 with a tighter floor. Positive pressure difference means that air is leaking from the crawl space to the classroom.

Figure 7 show results for the same building configuration as in the reference case but with climate scenario 4 (mild temperature and moderate wind). These two cases (Figure 3 and Figure 7) have the highest contaminant concentration in the classroom. In Figure 7, the stack effect is smaller, compared with the reference case, since the temperature difference between indoors and outdoors is smaller. This is why the pressure difference across the floor is smaller. The wind contributes to increasing the pressure difference across the floor. For this wind direction (northwest), the pressure difference across the floor increases with increased wind speed and results in more upward air leakage. Although more contaminants are leaking into the classroom in the reference case, the stack effect results in a higher ventilation rate than for the case in Figure 7. This is why the contaminant levels in both cases are the same even though the pressure difference across the floor is higher in the reference case.

The wind also affects the air exchange both in the classroom and in the crawl space. This is why the concentration in the crawlspace decreases as the wind increases. The effect from higher wind speeds means that more contaminants are leaking into the classroom from the crawl space, but since the classroom also becomes more ventilated, the concentration of contaminants in the classroom decreases at higher wind speeds. In fact, the most crucial scenario, in terms of high concentrations indoors, is when there is little wind and the outdoor temperature is close to the indoor temperature resulting a low air change rate in the classroom. 
The two cases Figure 3 and Figure 7 illustrate that it is not only the magnitude of the leaking air that determines the concentration of contaminants in the classroom. Also, the rate of ventilation is important.

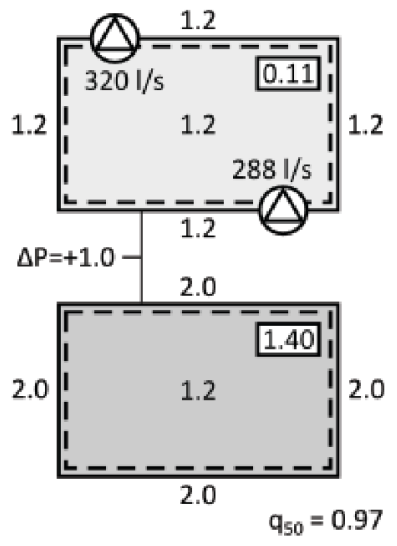

Fig. 7. Results from simulation with climate scenario 4. Positive pressure difference means that air is leaking from the crawl space to the classroom.

\subsection{Exhaust Fan in Crawlspace}

In this scenario, the building has an exhaust fan installed in the crawlspace. This is commonly done in schools with indoor air quality problems to prevent air from leaking from the crawlspace to the classroom. The typical procedure for installing an exhaust fan in the crawl space is making the crawlspace more airtight by sealing walls and floor. The flow of the exhaust fan is then calibrated so that a pressure difference of approximately $-5 \mathrm{~Pa}$ is achieved across the floor. Normally, the climate is not taken into consideration when calibrating the exhaust fan.

Figure 8 shows two simulation results with an exhaust fan installed in the crawl space. In Figure 8.a both the walls of the crawl space and the floor construction is made more airtight (compared to the reference case). In Figure 8.b only the floor is made more airtight. In both cases (Figure 8.a and 8.b) the exhaust fan is installed during climate scenario 3.a (calm day and $15^{\circ} \mathrm{C}$ ). The exhaust fan in the crawl space is adjusted so that a pressure difference across the floor of $5 \mathrm{~Pa}$ is achieved. The resulting airflow for the fan is 70 l/s (Figure 8.a) and 100 l/s (Figure 8.b). They higher airflow in the latter comes from the fact that the crawl space is less airtight. Figure 8 shows the results from these building configurations for a climate scenario 3.b (i.e. with wind).

Figure 8 illustrates that for the less airtight crawl space (Figure 8.b), a higher exhaust flow is needed to achieve a pressure difference across the floor (because of the crawl space being less airtight). Also, in the leakier crawl space (Figure 8.a), the pressure difference across the floor is higher compared to the more airtight crawl space. The reason is that the pressure difference across the floor in the leakier crawlspace is more sensitive to wind. When the wind increases, the pressure difference across the floor increases and it increases more if the crawlspace is leakier. Both cases show that not only the pressure difference across the floor construction needs to be considered to avoid air leakage from the crawl space to the classroom. Also, the climate and airtightness are important.

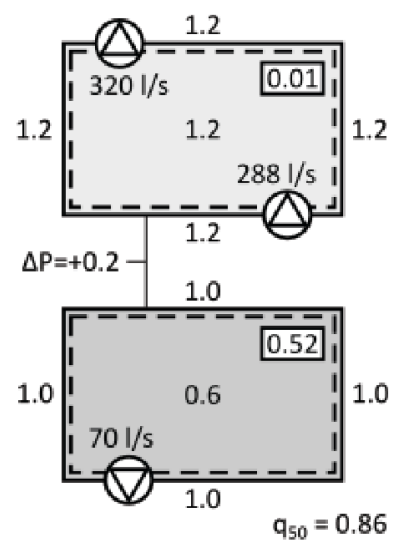

a)

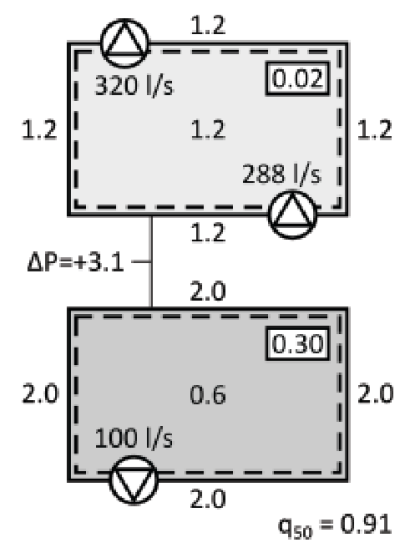

b)
Fig. 8. Crawl space with an exhaust fan during climate scenario 3.b. The exhaust fan in the crawl space have (in both cases) been adjusted to achieve a pressure difference across the floor of $-5 \mathrm{~Pa}$. a) with crawl space walls and floor made more airtight b) with crawl space walls made more airtight. Positive pressure difference means that air is leaking from the crawl space to the classroom.

\subsection{Decreased Ventilation}

It is common to turn down the ventilation rates in school buildings during nights, weekends and holidays to save energy. Figure 9 shows results from climate scenario 1 (without wind) where the ventilation is turned down to half of its normal rate. The pressure difference across the floor is almost unaffected by the decrease in ventilation. However, since the ventilation rate is smaller, the leakage of contaminants from the crawl space results in a higher concentration in the classroom. If the ventilation is turned down during night-time it may take several hours after the ventilation has been turned on to normal rates before the concentration reaches a new steady state.

It is important to note that even though the balanced ventilation system only has minor influence on the pressure difference across the floor. It is likely to be different for a more airtight building. 

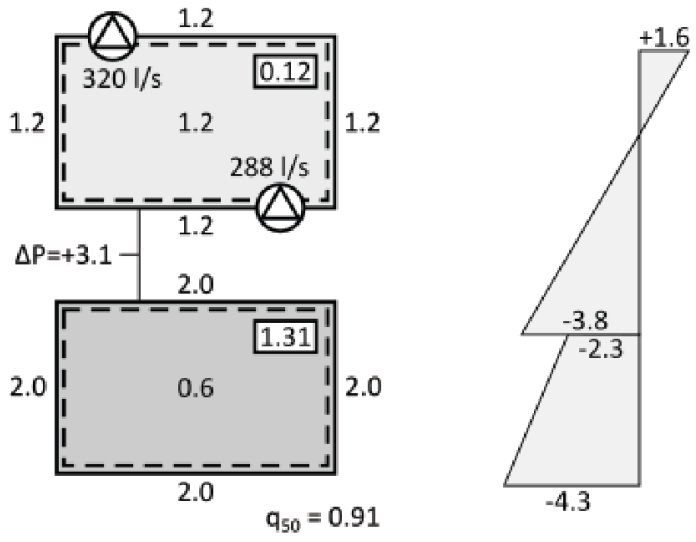

Fig. 9. Reduced ventilation rates. Positive pressure difference means that air is leaking from the crawl space to the classroom.

Table 2. Summary of the simulation results where the airtightness of different parts has been altered. All simulations are simulated with climate scenario 1 . For more detailed information see Figure 3 to 6.

\begin{tabular}{|l|c|c|c|c|}
\hline $\begin{array}{l}\text { Building } \\
\text { Configuration }\end{array}$ & $\begin{array}{l}\text { Reference } \\
\text { Case }\end{array}$ & $\begin{array}{l}\text { Tight } \\
\text { Crawlspace }\end{array}$ & $\begin{array}{l}\text { Tight } \\
\text { Floor }\end{array}$ & $\begin{array}{l}\text { Tight } \\
\text { Roof }\end{array}$ \\
\hline $\begin{array}{l}\text { Pressure } \\
\text { Difference }\end{array}$ & +1.6 & +0.8 & +3.1 & +1.4 \\
\hline $\begin{array}{l}\text { Concentration } \\
\text { Classroom }\end{array}$ & 0.11 & 0.12 & 0.12 & 0.12 \\
\hline $\begin{array}{l}\text { Concentration } \\
\text { Crawlspace }\end{array}$ & 1.0 & 1.62 & 1.31 & 1.08 \\
\hline
\end{tabular}

\section{Discussion}

Generally, the pressure difference increases with increased wind speed for most wind directions. However, for the simulations in this paper, wind pressure is taken as an average value for each surface and building shape and the effect from surrounding obstacles are not considered. Also, all building surfaces have evenly distributed leakages. This means that the wind direction has minimal effect on the building pressure distribution. It is likely that some wind directions can have a major impact on the pressure difference across the floor if the leakage distribution is more uneven, which is also shown in measurements. Further investigations will be made to study additional building configurations and uneven leakage distribution in combination with multi-zone modelling. Monte Carlo simulations will be made to capture a wider range of input variables.

\section{Conclusions}

This paper presents numerical simulations of pressure differences and contaminant levels for five building configurations and several climate scenarios with temperatures ranging from $-20{ }^{\circ} \mathrm{C}$ to $15{ }^{\circ} \mathrm{C}$ and wind speeds from $0 \mathrm{~m} / \mathrm{s}$ to $15 \mathrm{~m} / \mathrm{s}$. For leaky buildings, the ventilation rate in the classroom increases with increased wind speed. Even though the pressure difference across the floor also increases (and results in more air leaking from the crawl space to the classroom), the combined effect is reduced contaminant concentration in the classroom. Similarly, high winds also mean that the crawl space is more ventilated which results in lower contaminant concentrations in the crawl space.

The worst climate scenario, in terms of high concentrations in the classroom, occurs during mild weather with low wind speeds. The reason is that the increased ventilation from higher wind speeds contributes more to reducing the concentration than the inflow of contaminants caused by the increased pressure difference from wind and stack-effect.

In case of contaminant transport from a crawl space to a room (or suspicions thereof), common measures are to install a crawl space exhaust ventilation and additional ventilation in the classroom.

When adjusting the exhaust fan in the crawlspace to achieve $-5 \mathrm{~Pa}$ pressure difference across the floor, the climate at the time of adjustment, as well as the airtightness of the crawl space, needs to be considered in order to ensure that the pressure difference is not reversed when the weather changes.

Also, when installing additional ventilation, penetrations might cause additional leakages in the upper part of the building which will increase contaminant transport from the crawl space. However, this is compensated for by the increased ventilation rate in the classroom.

Making the floor in the classroom more airtight reduces the number of air leakage paths but increases the pressure difference across the floor, leading to a minor increase in contaminant levels in the classroom.

\section{Acknowledgement}

The research is funded by Formas, the Swedish Research Council for Environment, Agricultural Sciences and Spatial Planning, which is greatly acknowledged.

\section{References}

1. Airaksinen, M., Pasanen, P., Kurnitski, J. \& Seppänen, O. Microbial contamination of indoor air due to leakages from crawl space: a field study. Indoor Air 14, 55-64 (2004).

2. Domhagen, F., Wahlgren, P. \& Hagentoft, C.-E. Method for Detecting Contaminant Transport through Leakages in a Condemned School. International Building Physics Conference (2018).

3. Domhagen, F., Wahlgren, P. \& Hagentoft, C.-E. Contaminant Transport through the Thermal Envelope: Evaluation of Airflows Based on Numerical Modeling and Field Measurements. Conference Proceedings ASHRAE (2019).

4. Orme, M. TN 51: Applicable Models for Air Infiltration and Ventilation Calculations. Air Infiltration and Ventilation Centre. (1999). 
5. Dols, W. S. \& Polidoro, B. J. CONTAM User Guide and Program Documentation Version 3.2. NIST TN 1887 (2015).

6. Feustel, H. E. \& Raynor-Hoosen, A. Fundamentals of the multizone air flow model - COMIS. Air Infiltration and Ventilation Centre. (1990).

7. Chan, W., Joh, I. \& Sherman, M. Analysis of Air Leakage Measurements from Residential Diagnostics Database. LBNL-5967E (2012)

8. Orme, M., Liddament, M. W. \& Wilson, A. Numerical Data for Air Infiltration and Natural Ventilation Calculations. Air Infiltration and Ventilation Centre. 100 (1994).

9. Sandberg, P.-I., Sikander, E., Wahlgren, P. \& Larsson, B. Lufttäthetsfrågorna i byggprocessenEtapp B. Tekniska konsekvenser och lönsamhetskalkyler [Airtightness in the construction process- Stage B. Technical consequences and profitability assessments]. SP Sveriges Tekniska Forskningsinstitut. (2007). 